\title{
The Family-of-Origin Scale: A Psychometric Review and Factor Analytic Study
}

\author{
Mary-Ellen Hemming ${ }^{1}$, Victoria Blackmer ${ }^{2} \&$ H. Russell Searight ${ }^{2}$ \\ ${ }^{1}$ Department of Psychology, University of Dayton, Dayton, Ohio, USA \\ ${ }^{2}$ Department of Psychology, Lake Superior State University, Sault Sainte Marie, Michigan, USA \\ Correspondence: H. Russell Searight, Department of Psychology, Lake Superior State University, 650 W. \\ Easterday Avenue, Sault Sainte Marie, MI., 49783, USA. Tel: 1-906-635-2188. E-mail: hsearight@1ssu.edu
}

Received: April 22, 2012

doi:10.5539/ijps.v4n3p34
Accepted: June 21, $2012 \quad$ Online Published: July 16, 2012

URL: http://dx.doi.org/10.5539/ijps.v4n3p34

\begin{abstract}
The Family-of-Origin Scale (FOS) is a 40-item rating scale in which respondents provide a retrospective assessment of the family in which they were raised. While the FOS was found to be psychometrically sound, there has been a history of controversy about the scale's factor structure. A recent study published in this journal (Petrogiannis \& Softas-Nall, 2010) found a seven factor solution for the FOS. After reviewing the research on the FOS, including factor analytic studies, we present and interpret the results of a factor analysis based on data obtained from a U.S. university sample in which nine factors emerged.
\end{abstract}

Keywords: family assessment, psychometrics, Family-of-Origin theory

\section{Introduction}

\subsection{Background of the Family-of-Origin Scale}

Within family therapy, the family of origin is the basis of both psychodynamic and Bowenian approaches to treatment. Bowen's (1978) theory best elaborates on the impact of the family of origin on adult mental health. He indicates that there are two key dimensions - the intellectual-emotional dichotomy and the tension between togetherness and individuality. When these dimensions are appropriately balanced, an individual is said to be well differentiated. A well-differentiated person is one that is able to maintain intimate relationships while simultaneously possessing a strong sense of individual identity that is maintained despite familial pressures. One of the few scales based in family therapy theory, The Family-of-Origin Scale (FOS; Hovestadt, Anderson, Piercy, Cochran, \& Fine, 1985) assesses differentiation through its two primary dimensions of Autonomy and Intimacy.

Other historically oriented family therapists, such as the object relations school, suggest that the family of origin exerts its impact through internalized representations of important relationships -typically those between a parent and child (Nichols, 2011). These internalized objects, in turn, serve as unconscious models of close relationships and are likely to be activated when intimate relationships are being established in young adulthood. Object relations theorists believe that individuals project relationship expectations on to intimate others and may unconsciously try to mold important others according to these representations (Framo, 1976). Importantly, from this perspective, the family that is internally represented, whether it is objectively accurate, is the relationship representation that guides formation of intimate relationships in adulthood (Searight, 1997).

The Family of Origin Scale (FOS; Hovestadt, et al., 1985) is a 40 item retrospective instrument in which individuals rate the family in which they were raised. Conceptually, the FOS is based upon two overarching constructs-Autonomy and Intimacy - each of which is represented by five subscales. The subscales were influenced by Beavers' and colleagues description of five constructs characterizing healthy families: power structure, family individuation, acceptance of separation and loss, perceptions of reality, and affect (Lewis, Beavers, Gossett, \& Phillips, 1976). Beginning with its original publication in 1985, the FOS has been used in a variety of studies. For example, an adolescent version of the FOS was administered to clinical and non-clinical samples of adolescents currently residing with their families and found that the scale discriminated between adolescents in substance abuse treatment, psychiatric inpatient programs, and non-clinical groups (Niedermeier, Searight, Handal, Manley, \& Brown, 1995; Searight, Manley, Binder, Krohn \& Rogers. 1991).

During the first decade after its publication, the FOS was the subject of considerable controversy. Much of this 
controversy centered on the scale's construct validity, which was examined in a series of factor analytic studies. A key issue in this controversy was whether the FOS does indeed measure multiple distinct aspects of one's family of origin or whether adults retrospectively rating their families perceive their early family experiences as "all good" or "all bad" (Gavin \& Wamboldt, 1992; Kline \& Newman, 1994; Lee, Gordon, \& O’Dell, 1989; Mazer, Mangrum, Hovestadt \& Brashear, 1990; Schouten, 1996).

\subsection{The Family-of-Origin Scale: Psychometric Properties}

Traditional psychometric studies consistently found that the FOS was reliable. There was also evidence of discriminant validity with some support for construct validity.

Hovestadt et al. (1985), in the original FOS study, reported two week test-retest reliabilities of .97 for the scale overall with a median of .77 for the 20 Autonomy items and .73 for Intimacy. Internal consistency, as measured by Chronbach's alpha, was .97 (Hovestadt, et al., 1985).

Customary construct and criterion validity for scales of this type are somewhat challenging to establish since the instrument reflects a specific perspective on family health. However, in keeping with object relations theory, it is likely that "...the individual's perception ... [of their family]... may be a more proximal determinant of the rating than the actual health of the family, itself " (Gavin \& Wamboldt, 1992; p. 186). It is likely that external ratings of family functioning by a non-relative and even ratings by members of the same family may differ (Gavin \& Wamboldt, 1992) since everyone is likely to have a unique internal representation of their family-of-origin experience.

With this caveat, there have been a number of studies suggesting that the FOS meets conventional psychometric standards for construct and criterion validity. Support for construct and criterion validity come from studies in which the FOS was significantly and positively correlated with other established family assessment measures such as the Family Relations Index from the Family Environment Scale (Gavin \& Wamboldt, 1992; Holahan \& Moos, 1982), and Affectional and Associational Solidarity Toward Mother and Father measures (Bengston \& Scharder, 1985; Gavin \& Wamboldt, 1992). In addition, each of two FOS short forms generated by Ryan et al. (1995) were found to be associated with the Family History of Distress section of the Marital Satisfaction Inventory (Snyder, 1982).

Less direct support for construct validity comes from research in which the relationship between the FOS and individual measures of adjustment are examined. In this regard, the FOS has been found to be significantly and positively associated with the 16 Personality Factor scale's dimensions of emotional stability, conscientiousness and practicality (Lee, Gordon \& O'Dell, 1989). Lower total FOS scores, suggesting a lower level of family health, were associated with 16 PF dimensions assessing apprehensiveness, dependence on others, tension and lower emotional stability (Lee, et al., 1989). Yelsma and colleagues found that an empirically-derived, abbreviated 22 item version of the FOS correlated with three dimensions of the Toronto Alexithymia Scale-"impaired abilities to identify feelings, impaired abilities to describe feelings, and externally oriented thinking processes" (p. 359). The inverse association with affective measures and the FOS is compatible with Bowen's view of individual well-being as reflecting the ability to choose between emotional and cognitive responses to others.

One approach to determining a scale's criterion and construct validity-particularly when the conceptual background of the instrument makes it difficult to find another, psychometrically-established instrument assessing a related construct-- is through the contrasted groups approach. Two studies found that the FOS discriminated between self-defined adult children of alcoholics (ACOAs) and non-clinical groups. Capps and colleagues (Capps, Searight, Russo, Temple, \& Rogers, 1993) found that self-defined adult children of alcoholics (ACOA) obtained significantly lower scores on all 10 subscales as well as the total FOS score compared with a sample of undergraduate and graduate university students. A discriminant function analysis based upon the FOS, correctly classified $88 \%$ of the participants into ACOA and non-ACOA groups. A recent study of African American undergraduate students found significant differences between ACOAs and non-ACOAs on the total FOS score and corresponding differences in alcohol consumption (Hall, 2010).

A recent Polish study found that adolescents with eating disorders (bulimia and anorexia) as well as those with major depressive disorder scored lower on several subscales on both the autonomy and intimacy dimensions of the FOS (Jozefik \& Pilecki, 2010). Lee, Gordon, and O'Dell (1989) found that FOS scores discriminated between psychotherapy patients and non-patients. However, of note, pre-post FOS scores of those receiving a course of psychotherapy did not differ- suggesting that these retrospective perceptions of one's family have robust stability. 


\subsection{The Family-of-Origin Scale: Factor Structure}

The factor structure of the FOS has significant implications for the conceptual model upon which the scale is based. Hovestadt et al. (1985) viewed the instrument as assessing two overarching dimensions, Autonomy and Intimacy, with five subscales associated with each. At minimum, it would be expected that factor analytic studies would yield two factors accounting for approximately equal amounts of the total variance.

Table 1. The Family-of-Origin Scale: previous factor analytic studies

\begin{tabular}{|c|c|c|c|}
\hline Authors & Participants & Number of Factors & $\begin{array}{l}\text { Variance Accounted for by } \\
\text { Factors I-V }\end{array}$ \\
\hline Lee, Gordon, \& O’Dell (1989) & $\begin{array}{l}100 \text { participants- patients in or } \\
\text { seeking psychotherapy; } 40 \\
\text { males-median age }=35 ; 60 \\
\text { females-median age }=35\end{array}$ & 10 & $\begin{array}{l}\mathrm{I}=38.7 \% \\
\mathrm{II}-6.0 \% \\
\mathrm{III}=5.5 \% \\
\mathrm{IV}=4.6 \% \\
\mathrm{~V}=3.6 \%\end{array}$ \\
\hline Mazer, et al. (1990) & $\begin{array}{l}442 \text { undergraduate students; age } \\
\text { range: } 18-26\end{array}$ & 7 & $\begin{array}{l}\mathrm{I}=40.0 \% \\
\mathrm{II}=4.8 \% \\
\mathrm{III}=4.0 \% \\
\mathrm{IV}=3.2 \% \\
\mathrm{~V}=3.0 \%\end{array}$ \\
\hline Mazer, et al. (1990) & 340 college sophomores & 7 & $\begin{array}{l}\mathrm{I}=41.0 \% \\
\mathrm{II}=4.9 \% \\
\mathrm{III}=4.1 \% \\
\mathrm{IV}=3.3 \% \\
\mathrm{~V}=2.9 \%\end{array}$ \\
\hline Gavin and Wamboldt (1992) & $\begin{array}{l}63 \text { "premarital couples"-- mean age } \\
\text { males: } 25.5 \text { yrs, females: } 24.4 \text { yrs }\end{array}$ & 10 & $\begin{array}{l}I=43.4 \% \\
I I=6.8 \% \\
I I I=4.9 \% \\
I V=4.0 \% \\
V=3.3 \%\end{array}$ \\
\hline Kline and Newman (1994) & 162 males; mean age: 35 yrs. & 10 & $\begin{array}{l}\mathrm{I}=20 \% \\
\mathrm{II}=16 \% \\
\mathrm{III}=4 \% \\
\mathrm{IV}=4 \% \\
V=4 \%\end{array}$ \\
\hline $\begin{array}{l}\text { Ryan, Kawash, Fine, \& Powell } \\
\text { (1994) }\end{array}$ & $\begin{array}{l}132 \text { participants-from random } \\
\text { telephone directory selection and from } \\
\text { marital and family therapists; } 69 \\
\text { males-mean age }=36.6 \text { yrs; } 63 \text { females; } \\
\text { mean age }=39.3 \text { yrs }\end{array}$ & 7 & $\begin{array}{l}\mathrm{I}=17.91 \% \\
\mathrm{II}=12.88 \% \\
\mathrm{III}=10.96 \% \\
\mathrm{IV}=10.24 \% \\
V=7.48 \%\end{array}$ \\
\hline Petrogiannis and Softas-Hall (2010) & $\begin{array}{l}306 \text { Greek university students; } 81 \\
\text { males, } 225 \text { females; mean age: } 21 \text { yrs }\end{array}$ & 7 & $\begin{array}{l}I=37.8 \% \\
I I=5.70 \% \\
I I I=4.07 \% \\
I V=3.72 \% \\
V=3.47 \%\end{array}$ \\
\hline
\end{tabular}


Published factor analytic studies of the FOS are summarized in Table 1. As noted by Petrogiannis and Softas-Hall (2010), nearly all of the published factor analytic studies of the FOS have employed principal components analysis with some investigators reporting orthogonal varimax rotations. Of seven factor analytic studies of the FOS, five have yielded a single factor accounting for approximately $40 \%$ of the variance and a series of smaller factors each of which accounts for $7 \%$ or less of the total variance. However, Kline and Newman (1994) and Ryan et al. (1994) found a more evenly distributed pattern of variance accounted for by two to four factors (See table 1). As noted above, most factor analytic studies do not directly support a two factor model with Kline and Newman's study being a possible exception. They indicated that most of the variance in the scale can be accounted for by one unitary factor. Other studies suggested a 7 to 9 factor structure for the scale - indirectly suggesting that the FOS does measure multiple distinct components of the respondent's family of origin.

Those finding a large initial factor such as Lee, Gordon, and O'Dell have concluded that respondents tend to see their families as "all good" or "all bad", and do not differentiate between specific dimensions of family functioning. Similarly, Yelsma and colleagues (2000) concluded that one factor that included 22 items accounts for most (44\%) of the interpretable variance in the FOS. Based upon the factor loadings, they concluded that this single factor assesses "[the]individual's perceived level of expressive atmosphere in his/her family of origin" (p. 357). These 22 items comprised a new instrument, the Family-of-Origin Expressive Atmosphere Scale (Yelsma, Hovestadt, Anderson, \& Nilsson, 2000)

\subsection{Current Study}

Multiple literature searches did not locate any factor analytic studies on the FOS published in in the past decade - with one recent exception. Petrogiannis and Softas-Hall (2010) published a factor analysis of the FOS in a Greek sample. These authors found a total of seven factors and an initial factor, accounting for nearly $38 \%$ percent of the variance. The purpose of the current study is to compare results of the Greek investigation of the factor structure of the FOS with a contemporary sample of U.S. university students.

\section{Method}

\subsection{Participants}

The data that served as the basis for this factor analysis was originally obtained in a study of eating behavior, body image, and perceptions of the family-of-origin. The study is described elsewhere (Blackmer, Searight, \& Ratwik, 2011). Participants were 103 university students at a Midwestern U.S. University. By gender, there were 47 were males and 56 females. Ages ranged from 18 to 25 years with a mean of 19.84 years). Approximately $90 \%$ of the sample was of White European background (Blackmer, Searight, \& Ratwik, 2011).

\subsection{Instrument and Procedure}

The Family-of-Origin Scale (FOS; Hovestadt, et al., 1985) is a 40 item measure with each item rated on a 1 to 5 Likert scale according to the respondent's level of agreement with each statement (1=Strongly Disagree; $5=$ Strongly Agree). The items are all worded in the past tense with the instruction to respond based on the respondent's experience growing up in their family. The 40 items are grouped into two overarching dimensions - each of which includes five subscales. The Autonomy dimension includes: Openness to Others, Clarity of Expression, Responsibility, Respect for Others, Acceptance of Separation and Loss; while the Intimacy dimension is comprised of the Mood and Tone, Range of Feelings, Conflict Resolution, Empathy for Others and Trust subscales.

Twenty of the rated items are stated in the affirmative while the remaining twenty are stated negatively. To maintain uniformity, all of the negatively worded items are scored so that the highest rating ("5") indicates the respondent's strong disagreement with the item's content. As noted in the review above, the FOS has demonstrated reliability and validity.

The FOS protocols were scored according to Hovestadt, et al.'s (1985) guidelines. Individual items for each protocol were entered into an SPSS file for analysis.

Results of a principal components analysis were initially examined. To attempt to reduce overlap and optimize factor loadings, a Varimax rotation was conducted (Kline, 1994). To determine the number of factors in the solution, the criterion of an eigenvalue greater than one was used. 


\section{Results}

Table 2. Varimax rotation of Family-of-Origin Scale: factor loadings

\begin{tabular}{|c|c|c|c|c|c|c|c|c|c|}
\hline Items & 1 & 2 & 3 & 4 & 5 & 6 & 7 & 8 & 9 \\
\hline 1 & & .373 & & & & & & & .416 \\
\hline 2 & .304 & .627 & & & .400 & & & & \\
\hline 3 & .606 & .340 & & & .309 & & & & \\
\hline 4 & .369 & .322 & & & & & & .464 & \\
\hline 5 & & & & & & & & .749 & \\
\hline 6 & .334 & .537 & & & & .319 & & & \\
\hline 7 & & .660 & & & & & & & \\
\hline 8 & & & & & & .743 & & & \\
\hline 9 & & & & & & & .744 & & \\
\hline 10 & & & .801 & & & & & & \\
\hline 11 & .382 & & & & & .393 & & & \\
\hline 12 & & & .609 & & & & & & \\
\hline 13 & & .446 & & & .423 & & .397 & & .439 \\
\hline 14 & & & & & & & & & .679 \\
\hline 15 & .433 & .446 & & & & & .303 & & .383 \\
\hline 16 & & & & & & & .740 & & \\
\hline 17 & & .632 & & & .344 & & & .357 & \\
\hline 18 & & .366 & & & & & & .551 & \\
\hline 19 & & .307 & & .423 & & .314 & & & .319 \\
\hline \multicolumn{10}{|l|}{20} \\
\hline 21 & & .715 & & & & & & & \\
\hline 22 & .537 & .524 & & & & & & & \\
\hline 23 & .332 & .319 & & & .337 & & & & \\
\hline 24 & & & & .438 & & .567 & .419 & & \\
\hline 25 & & & & .306 & & & & & \\
\hline 26 & & & & & .745 & & & & \\
\hline 27 & & & & .339 & & .463 & .431 & & \\
\hline 28 & & & & .622 & & & & .351 & \\
\hline 29 & & & & .565 & & & & & \\
\hline 30 & .615 & .390 & & & & & & & \\
\hline 31 & .399 & .614 & & & & & & & .303 \\
\hline 32 & .704 & & & & & & & & \\
\hline 33 & .426 & & & & .575 & & & & \\
\hline 34 & .337 & & .359 & .610 & & & & & \\
\hline 35 & .401 & .331 & & .508 & & & & & \\
\hline 36 & & & .608 & & & .302 & & & \\
\hline 37 & & & & & .543 & & & & \\
\hline 38 & .318 & & & .307 & & .484 & & .364 & \\
\hline 39 & .740 & & .324 & & & & & & \\
\hline 40 & .692 & & & .314 & & & & & \\
\hline
\end{tabular}

Factor loadings above .30 are included above

The total mean FOS score as well as that for males and females were comparable to figures reported by Petrogiannis \& Softas-Hall (2010). Of note, there were no statistically significant differences between the U.S. sample and the Greek participants on any of the individual items or for the total FOS score.

For the current sample of participants, the FOS demonstrated substantial internal consistency reliability with a Chronbach's alpha of .97 for the 40 item instrument. This value is consistent with alpha levels reported by Petrogiannis and Softas-Hall (2010) as well as by earlier FOS investigators (Gavin \& Wamboldt, 1992; 
Hovestadt, et al., 1985; Ryan et al., 1994).

A principal components factor analysis yielded a total of nine factors based on the criterion of an Eigenvalue greater than one. The initial factor accounted for $39 \%$ of the variance. When taken together, the factors emerging from the principal components analysis accounted for approximately $69 \%$ of the variance.

We then conducted a Varimax rotation which is depicted in Table 2. While nine factors were extracted and the overall variance explained was comparable to that obtained in the principal components analysis (see Table 3), the factor loadings, based on the principle of orthogonality, led to a more distinct pattern. Compared with the principal components pattern, the Varimax analysis, suggested that, while there was some overlap of items between factors, this redundancy was reduced allowing greater clarity of interpretation (Hair, Anderson, Tatham, \& Grablowsky, 1979).

Table 3. Eigenvalues and percentage of variance accounted for by 9 factor solution (principal components and varimax rotation)

\begin{tabular}{lcclccc}
\hline & \multicolumn{3}{c}{ Initial Eigenvalues } & \multicolumn{3}{c}{ Rotation Sum of Squares Loadings } \\
\cline { 2 - 6 } Factor & Total & $\begin{array}{l}\text { Percentage of } \\
\text { Variance }\end{array}$ & $\begin{array}{l}\text { Cumulative } \\
\text { Percentage of } \\
\text { Variance }\end{array}$ & $\begin{array}{l}\text { Total } \\
\text { Percentage of } \\
\text { Variance }\end{array}$ & $\begin{array}{l}\text { Cumulative } \\
\text { Percentage } \\
\text { of Variance }\end{array}$ \\
\hline 1 & 15.641 & 39.102 & 39.102 & 4.926 & 12.314 & 12.314 \\
2 & 2.181 & 5.452 & 44.554 & 4.644 & 11.610 & 23.924 \\
3 & 1.944 & 4.860 & 49.414 & 3.718 & 9.295 & 33.219 \\
4 & 1.674 & 4.186 & 53.599 & 2.883 & 7.208 & 40.427 \\
5 & 1.497 & 3.742 & 57.342 & 2.541 & 6.353 & 46.780 \\
6 & 1.303 & 3.529 & 60.601 & 2.530 & 6.326 & 53.106 \\
7 & 1.215 & 3.038 & 63.639 & 2.482 & 6.205 & 59.311 \\
8 & 1.200 & 3.001 & 66.640 & 2.185 & 5.463 & 64.773 \\
9 & 1.033 & 2.582 & 69.222 & 1.780 & 4.449 & 69.222 \\
\hline
\end{tabular}

\section{Discussion}

The current U.S. university sample obtained similar individual item and total FOS scores as in Petrogiannis and Softas-Nall's (2010) Greek sample. While suggesting that the FOS is generalizable to other cultures, it is not congruent with the view of McGoldrick and others emphasizing cultural differences in family processes. For example, Greek-American families are characterized as being particularly emotionally expressive (McGoldrick, Pierce, \& Giordano, 1995).

In addition, a recent U.S. study of ethnic differences in FOS scores found that African-American respondents rated their families as higher in Respect for Others and Range of Feelings than Asian, White or Hispanic respondents (Kane, 1998).

In the current study, we conducted a Varimax factor rotation in which the factor axes are maintained as orthogonal (Kline, 1994). While the total variance accounted for by the factor solution is comparable to previous reports (See Tables 1 and 3), the distribution of variance differs. Instead of being based on the amount of variance extracted, the Varimax rotation minimizes the correlations among the resulting factors (Kline, 1994). As a result, there tend to be fewer items loading on a given factor and there is often a reduction in the extent to which an item loads on multiple factors (Hair, Anderson, Tatham, \& Grablowsky, 1979). In terms of the percentage of variance explained, our first seven factors had similar explanatory power as the seven factor solution reported by Petrogiannis and Softas-Hall (2010). Similarly, in their study, the first factor accounted for nearly $38 \%$ of the total explained variance. This overall pattern is similar to four of the previous six reported factor analytic studies with the FOS published between 1989 and 1994. The issue of whether the FOS is a multi-dimensional versus unitary instrument is, to some extent, a matter of how one interprets the variance accounted for by each factor. While Factor I explained substantially more of the variance in the overall factor structure, the remaining eight factors did contribute additional dimension helpful in understanding family 
functioning.

In examining the items loading at .4 and above on Factor I, it appears that a common shared dimension was the emotional climate and extent to which open communication was encouraged (22. "The atmosphere in my family was cold and negative;" 40. "I remember my family as being warm and supportive;" 15. "My family encouraged me to express my views openly;" 32. "In my family, certain feelings were not allowed to be expressed;" 39. "My family had an unwritten rule: Don't express your feelings.").

Many of the FOS items dealing with conflict resolution and related communication skills loaded on Factor II (7. "Conflicts in my family never got resolved;" 13. "Resolving conflicts in my family was a very stressful experience;" 31. "We usually were able to work out conflicts in my family; 6." My parents encouraged family members to listen to one another.").

Factor III contained fewer items. While several communication items (39. " My family had an unwritten rule: Don't express your feelings.") loaded on this factor, this dimension also reflected issues with emotional reactions to separation and loss (10. "We talked about our sadness when a relative or friend died;" 36. "When someone important to us moved away, our family discussed our feelings of loss.").

Factor IV appeared to emphasize a family climate of openness to members' perspectives (28. "I found it difficult to express my own opinions in my family;" 34." I found it easy in my family to express what I thought and how I felt;" 35. "My family members were usually sensitive to one another's feelings.").

A family climate in which others - particularly those outside the immediate family - are viewed with some guardedness (26. "In my family, I learned to be suspicious of others;" 33. "My family believed that people usually took advantage of you.") characterized Factor V along with problems with addressing differences within the family (13. "Resolving conflicts within my family was a very stressful experience;" 17. "My attitudes and feelings frequently were ignored or criticized in my family;" 23. "The members of my family were not very receptive to one another's views.").

Examination of the items associated within Factor VI did not indicate a strong unifying theme but did suggest a positive, optimistic view of relationships (8. "My family taught me that people were basically good;" 24. " I found it easy to understand what other family members said and how they felt;" 27. "In my family, I felt I could talk things out and settle conflicts.").

Factor VII appeared to have some redundancy with the dimensions above which emphasized a climate that encouraged or discouraged communication and levels of transparency within the family (9. "I found it difficult to understand what other family members said and how they felt;" 16 . "I often had to guess at what other family members thought or how they felt;" 24. "I found it easy to understand what other family members said and how they felt.").

Most of the items loading on factor VIII coalesced around the theme of personal responsibility (5. "People in my family often made excuses for their mistakes;" 18. "My family members rarely expressed responsibility for their actions;" 5. "People in my family often made excuses for their mistakes.").

Finally, Factor IX appeared to capture a family climate in which individuality was encouraged and in which the expression of a range of feelings and beliefs were supported (14. "My family was receptive to the different ways various family members viewed life;" 12. "In my family, I expressed just about any feeling I had;" 19. "In my family, I felt free to express my own opinions.").

The current factor analysis suggests that there is a primary component to the FOS assessing the overall emotional climate of the rater's family and the quality of communication. Other dimensions assessed by the scale appear to include conflict resolution, and support for and openness to multiple viewpoints including perspectives originating outside the family. While the factors do not resemble the dimensions originally described by the scale's developers, the factors do provide useful information about family processes and climate that could be useful in the clinical setting.

\section{References}

Bengston, V. L., \& Schrader, S. S. (1982). Parent-child relations. In D. J. Mangen \& W. A Peterson (Eds.), Research instruments in social gerontology: Vol. 2. Social roles and social participation (pp. 155). Minneapolis, MN: University of Minnesota Press.

Blackmer, V., Searight, H. R., \& Ratwik, S. (2011). The relationship between eating attitudes, body image, and perceived family-of-origin climate in college athletes. North American Journal of Psychology, 13, 441-452.

Bowen, M. (1978). Family therapy in clinical practice. New York: Jason Aronson. 
Capps, S., Searight, H. R., Russo, J. R., Temple, L., \& Rogers, B. (1993). The Family-of-Origin Scale: Discriminant validity with adult children of alcoholics. American Journal of Family Therapy, 21, 274-277. http://dx.doi.org/10.1080/01926189308250926

Framo, J. L. (1976). Family of origin as a therapeutic resource for adults in marital and family therapy: You can and should go home again. Family Process, 15, 193-210. http://dx.doi.org/10.1111/j.1545-5300.1976.00193.x

Gavin, L. A., \& Wamboldt, F. S. (1992). A reconsideration of the family-of-origin scale. Journal of Marital and Family Therapy, 18, 179-188. http://dx.doi.org/10.1111/j.1752-0606.1992.tb00928.x

Hair, J., Anderson, R. E., Tatham, R. L., \& Grablowsky, B. J. (1979). Multivariate data analysis. Tulsa. OK: PPC Publishers.

Hall, J. C. (2010). Childhood perceptions of family, social support, parental alcoholism and later alcohol use among African American college students. Journal of Substance Use, 15, 157-165. http://dx.doi.org/10.3109/14659890903013083

Holahan, C. J., \& Moos, R. H. (1983). The quality of social support: Measures of family and work relationships. British Journal of Clinical Psychology, 22, 157-162. http://dx.doi.org/10.1111/j.2044-8260.1983.tb00596.x

Hovestadt, A. J., Anderson, W. T., Piercy, F. P., Cochran, S. W., \& Fine, M. (1985). A family-of-origin scale. Journal of Marital and Family Therapy, 11, 287-297. http://dx.doi.org/10.1111/j.1752-0606.1985.tb00621.x

Jozefik, B., \& Pilecki, M. W. (2010). Perception of autonomy and intimacy in families of origin of patients with eating disorders with depressed patients and healthy controls. A transgenerational perspective-Part $I$. Archives of Psychiatry and Psychotherapy, 4, 69-77.

Kline, P. (1994). An easy guide to factor analysis. New York: Routledge.

Kline, C. D., \& Newman, I. (1994). Factor structure of the Family-of-Origin Scale: Does this scale measure what its creators say it does? Journal of Marital and Family Therapy, 20, 47-52. http://dx.doi.org/10.1111/j.1752-0606.1994.tb01010.x

Lee, R. E., Gordon, N. G., \& O’Dell, J. W. (1989). The validity and use of the family-of-origin scale: A factor $\begin{array}{lllll}\text { analysis. Journal of Marital and Family Therapy, 15, } & \text { 19. }\end{array}$ http://dx.doi.org/10.1111/j.1752-0606.1989.tb00773.x

Mazer, G. E., Mangrum, O. L., Hovestadt, A. J., \& Brashear, R. (1990). Further validation of the family-of-origin scale: A factor analysis. Journal of Marital and Family Therapy, 16, 423-426. http://dx.doi.org/10.1111/j.1752-0606.1990.tb00060.x

Nichols, M. (2009). Family therapy: Concepts and Methods (9th Eds.). New York: Pearson Publishers.

Niedermeier, C. L., Searight, H. R., Handal, P. J., Manley, C. M., \& Brown, N. Y. (1995). Perceived family functioning among adolescent psychiatric inpatients: Validity of the Family-of-Origin Scale. Child Psychiatry and Human Development, 25, 252-265.

Petrogiannis, K., \& Softas-Hall, L. C. (2010). The Family of Origin Scale in Greece. International Journal of Psychological Studies, 2, 3-10.

Ryan, B. A., Powel, B., Kawash, G. F., \& Fine, M. (1995). Parallel short forms of the family of origin scale: Evidence of their reliability and validity. Journal of Psychopathology and Behavioral Assessment, 17, 283-291. http://dx.doi.org/10.1007/BF02229303

Schouten, P. (1996). Researchers discover what they already knew about the validity: The case of the

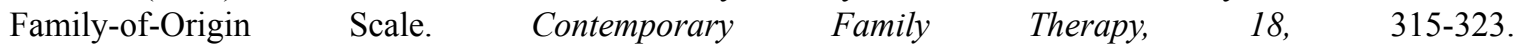
http://dx.doi.org/10.1007/BF02196731

Searight, H. R. (1997). Family of origin therapy and cultural diversity. Philadelphia: Taylor \& Francis.

Searight, H. R., Manley, C. M., Binder, A. F., Krohn, E., Rogers, B. J., \& Russo, J. R. (1991). The families of origin of adolescent drug abusers: Perceived autonomy and intimacy. Contemporary Family Therapy, 13, 71-81. http://dx.doi.org/10.1007/BF00892230

Snyder, D. K. (1981). The marital satisfaction inventory (MSI) manual. Los Angeles: Western Psychological Research. 
Yelsma, P. Hovestadt, A. J., Anderson, W. T., \& Nilsson, J. E. (2000). Family of origin expressiveness: Measurement, meaning, and relationship to alexithymia. Journal of Marital and Family therapy, 26, 353-363. http://dx.doi.org/10.1111/j.1752-0606.2000.tb00304.x 